\title{
Co-construction of turns at talk: Active listening or disruptions in conversation with persons who stutter?*
}

\author{
Marianne Lind ${ }^{\mathrm{a}, \mathrm{b}}$ and Hilda Sønsterud ${ }^{\mathrm{a}}$

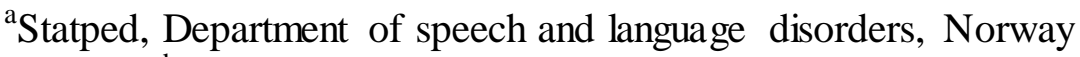 \\ ${ }^{\mathrm{b}} \mathrm{CoE}$ MultiLing, University of Oslo, Norway
}

\begin{abstract}
The present study applies conversation analysis in order to describe the form and function of co-constructed turns in conversations involving one or more persons who stutter. Coconstructed turns are turns at talk that are produced by more than one speaker in such a way that the turn is initiated by one speaker and completed by another. Examples in the data are classified according to an existing taxonomy distinguishing between slot fillers, extensions and completions. All these types are found in our data, albeit to different extents. External as well as internal reasons for this distributional variation are discussed. The main aim of the study is to illustrate the need for qualitative, context-sensitive approaches to research on verbal interaction in the field of fluency disorders and to focus on some clinical implications of such research findings.
\end{abstract}

Keywords: stuttering; conversation analysis; qualitative research; co-construction; turn taking; interruption

\section{Introduction}

Verbal communication and the disorders which may affect it, are complex phenomena whose explication requires a combination of research methods, qualitative as well as quantitative, applied to empirical data - language use - in a variety of linguistic and cultural contexts. As pointed out by several researchers, within the field of fluency disorders there is a strong tradition for quantitative, experimental research of various aspects of speech production and verbal communication (Acton, 2004; Bothe and Andreatta, 2004; Cheek, Onslow and Cream, 2004). This strong influence of the quantitative paradigm in research on fluency disorders, has led to a comparable shortage of studies using qualitative methodologies in order to investigate particular aspect of stuttering within various communicative contexts (cf. Hayhow and Stewart (2006) for a review of qualitative methodologies applied to research on stuttering).

The present study applies one type of qualitative methodology - conversation analysis - in order to investigate a specific type of turn taking behaviour - co-constructed turns - in conversations involving one or more persons who stutter (PWS). Co-constructed turns are turns at talk that are produced by more than one speaker in such a way that the turn is initiated by one speaker and completed by another (cf. below for a more detailed account of various types of co-constructed turns). This preliminary description of co-constructed turns intuitively reminds one of the concept of interruption. According to the Compact Oxford English

\footnotetext{
* Published in Journal of Interactional Research in Communication Disorders, 2014, vol 5, no. 2, pp. 141-165, doi : 10.1558/jircd.v5i2.141
} 
Dictionary (http://www.askoxford.com/) the verb interrupt means to 'stop the continuous progress of [something], stop (a person who is speaking) by saying or doing something, and break the continuity of [something]'. In other words, the concept of interruption carries with it negative connotations of interfering with, taking control over someone/something or breaking the progress of an (other-initiated) action.

The concept of interruption plays a central role in the types of advice that are regularly given to parents, teachers and others communicating verbally with a PWS. Some examples of these types of advice are given in (1) below.

(1) (a) Avoid guessing the word or finishing sentences - it is very tempting, but you may get it wrong or it may just make the person feel cross! ${ }^{1}$

(b) You may be tempted to finish sentences or fill in words. Try not to do so. ${ }^{2}$

Our aim is not to refute these pieces of advice totally. ${ }^{3}$ In many instances we think they serve an important purpose. However, we believe these pieces of advice carry an unfortunate implication that all instances of simultaneous talk or turn completing utterances are seen as instances of interruption. We would like to question this implication by examining turn taking behaviour in conversations where one or more of the participants is a PWS.

The amount and effect of interruption is one of the variables that have been analysed in conversations between stuttering and non-stuttering participants (e.g. Kelly, 1994; Kelly and Conture, 1992; Livingston, Flowers, Hodor and Ryan, 2000; Meyers and Freeman, 1985; Ryan, 2000). Most of these studies have been conducted within a quantitative paradigm, investigating behaviour across groups of speakers consisting of stuttering and non-stuttering children interacting with one of their parents. The group sizes vary between eleven and twenty children. The findings of these studies are equivocal. For example, Meyers and Freeman (1985) found that mothers of both stuttering and non-stuttering children interrupted the children's disfluent speech significantly more than they interrupted the children's fluent speech. Other studies (e.g. Kelly, 1994; Kelly and Conture, 1992; Ryan, 2000) have found no significant differences in parental interruptions of stuttering and non-stuttering children. In the literature, there are no certain findings of a negative effect of interruption on stuttering, either. Ryan (2000: 44) concludes: 'Interruption may be a normal conversational behaviour which plays little or no role in the development or maintenance of stuttering'. We also totally agree with his subsequent comment (Ryan, 2000: 44): 'This does not preclude the possibility that an individual child may be susceptible to interruption and may stutter in response to it'. This clearly warrants an individual, qualitative approach to the analys is of the form and function of various aspects of conversational behaviour.

Our focus in this study is mainly exploratory and descriptive, and our primary research questions concern the use (or non-use) of co-constructed turns in a few conversations where one or more of the participants is a PWS. We attempt to classify co-constructed turns following the taxonomy of Bockgård (2004), which is presented below. Finally, we discuss possible reasons for not participating in collaborative turn construction. Our main aim with this study is to focus on the need for context-sensitive and qualitative approaches to research on verbal interaction in the field of fluency disorders. This need has been pointed out by others (e.g. Tetnowski and Damico, 2004), and some research papers have been published (cf. the review by Hayhow and Stewart, 2006), but there is an obvious need for more research in this area, based on data from various linguistic and cultural contexts. 


\section{Theoretical background}

Research on conversation in different types of situational and cultural contexts has revealed that turns and sequences are the fundamental building blocks of conversation (Ford, Fox and Thompson, 2002; Sacks, Schegloff and Jefferson, 1974; Schegloff, 2007). They are among the phenomena that participants demonstrably treat as real and consequential for their interaction. A turn at talk is a period in the conversation during which a given participant has the right - but also the obligation - to present some type of sequentially relevant contribution to his or her co-participants in the interaction. In the capacity as speakers participants must meet both a demand for progressivity and an imperative to fill the temporal space with a relevant action (Lerner, 1996).

In the classical model of turn taking (Sacks et al., 1974), turns are perceived as unilateral phenomena, something the individual speaker alone is responsible for. Research on turn taking in various contexts has also confirmed the finding by Sacks et al. (1974: 706) that 'overwhelmingly, one party talks at a time'. However, research, not least by Lerner (1996, 2002), has revealed how turns on many occasions are produced collaboratively by two or more participants. Such co-production of turns is not a rare phenomenon in conversation, although the frequency and function of it differ contextually.

Collaboratively constructed turns have been described under various labels and defined in slightly various ways (cf. Bockgård (2004) for an overview of prior research into this field). The common feature of the various definitions, however, is that collaboratively constructed turns must consist of two parts produced by two different speakers, and that there must be some type of connection - syntactic, semantic, pragmatic and/or prosodic - between the two parts, in such a way that the second part is heard as a completion of the first part.

There are also different taxonomies of collaboratively constructed turns in the literature. In this study, we have chosen to follow the categorisation suggested by Bockgård (2004), since this is both comprehensive and based on a varied and quite large data base of conversations. ${ }^{4}$ He distinguishes between three main subtypes of co-constructed turns: slot fillers, extensions and completions. ${ }^{5}$ A slot filler occurs as a non-optional response by B to a specific type of question by $\mathrm{A}$. This question concerns a B-event (something that B has primary knowledge of) (Labov and Fanshel, 1977), and the question is formulated in such a way that a slot is left open for B to fill in. ${ }^{6}$ A's contribution is thus incomplete syntactically, semantically, pragmatically and prosodically. The following example from Bockgård (2004: 93) illustrates this type of construction (cf. the Appendix for a key to the transcription notation). ${ }^{7}$

(2) Four women talking about a common female acquaintance over a cup of coffee

1 A: hon ska vä åka ti Kanarieöarna nu den <SLOW tjusjunde SLOW> tro ja.

'she's going to the Canary Islands now on the

twentyseventh I think'

2 D: .. $[j a=$.

'yes'

3 B: [tjugàt] tonde?

'twentyeight'

4 A: .. va re tjugåttonde.

'was it on the twentyeight'

5 C: (0) ja[ha.] 


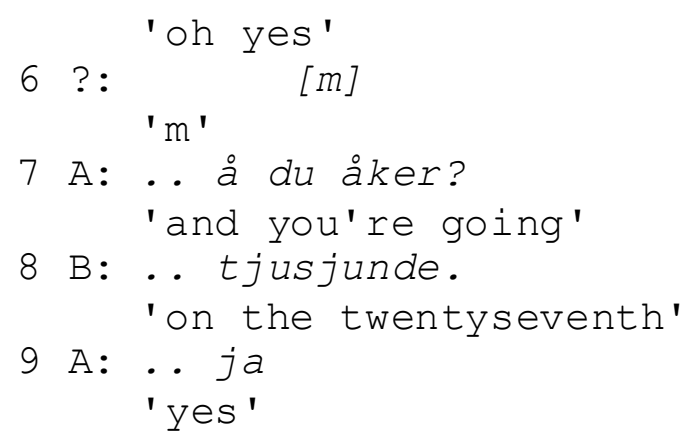

In line 7, A poses a question for B, which as Bockgård (2004: 93) points out, makes a response in the form of an answer immediately relevant. Since the question is directed specifically at one particular person, this participant (B) becomes responsible for providing the next relevant action in the conversation, as she does in line 8. Formally, the question by $\mathrm{A}$ is a syntactically and prosodically incomplete declarative sentence, where the slot for the syntactically obligatory adverbial has been left open. In other words, the utterance in line 7 paves the way for a quite specific type of utterance - a slot filler - in next turn position. Since slot fillers are required by the linguistic context, they are strongly projected in the interaction. Together, the utterances by $\mathrm{A}$ and $\mathrm{B}$ in lines 7 and 8 make up a collaboratively constructed turn, initiated by A and completed by B.

A turn-completing utterance by B may also be optional and follow a complete contribution by A. These types of completions are called extensions. For an utterance to function as an extension there must be a syntactic connection between the extension and the preceding utterance. Often extensions function as non-obligatory adverbials in relation to the prior utterance, as in example (3) translated from Bockgård (2004: 95).

(3) Two women discussing the price of strawberries

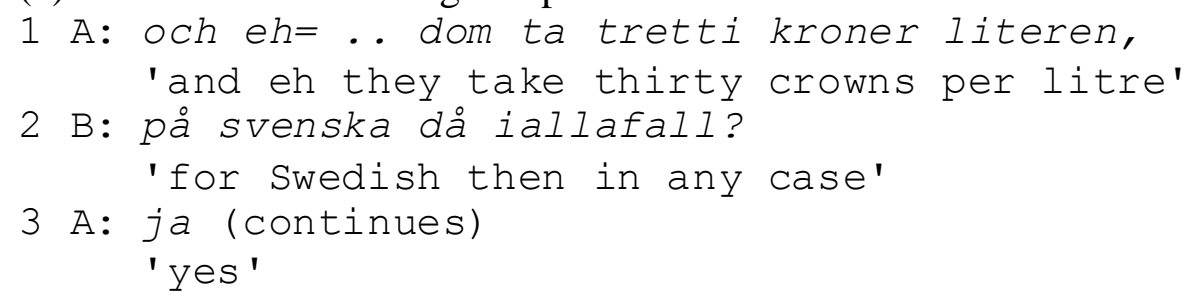

The utterance produced by A in line 1 is syntactically complete, and as Bockgård (2004: 95) points out, even though a continuation of the utterance is possible, it is not clearly projected. Nevertheless, in line 2, B produces an utterance which is heard as an addition - an extension of the utterance in line 1 . The utterance by $\mathrm{B}$ extends and recompletes the potentially complete utterance by A (cf. the observation by Bockgård (2004: 94) that a turn at talk can have several possible syntactic completion points, but only one that is realized in action). The reason why the utterance by $\mathrm{B}$ is heard as a completion of the utterance by $\mathrm{A}$ and not as a new, independent turn, must be sought in the particular sequential context in which the two utterances are produced. The sequential context may include for instance prosodic cues in A's utterance (a non-final prosodic contour) or sound prolongations and other markers of hesitation. The complementary nature of the two utterances is of course also found in the fact that there is a clear semantic and pragmatic link between the utterance by B and the prior utterance by A. Together the two utterances make up a collaboratively constructed turn. 
The third type of co-constructed turn is the completion. This is an optional, but turncompleting utterance by B which follows a syntactically and in other ways incomplete utterance by A. Thus, the main difference between completions and extensions is that the former follows an incomplete utterance whereas the latter is found after an utterance which is potentially syntactically complete. Completions may be projected by or attributed to some sign of trouble in A's utterance. This is the case in example (4) translated from Bockgård (2004: 95).

(4) Two women describing a man to a third participant in the interaction

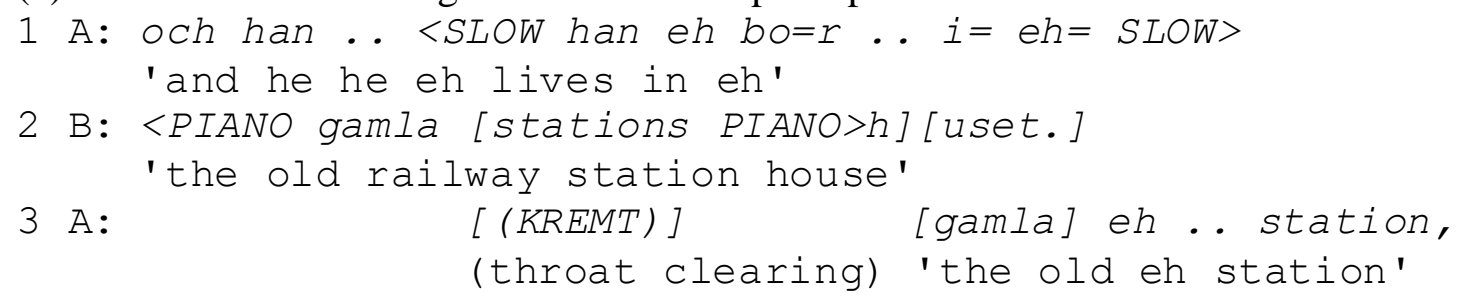

In line 1, A produces a syntactically and in other ways incomplete utterance, and there are signs of difficulties on A's part with her management of the utterance production (cf. the change in speech tempo, the sound prolongations and the markers of hesitation). B's utterance in line 2 completes A's utterance on every level, syntactically, prosodically, semantically and pragmatically. Together these two utterances make up a collaboratively constructed turn, and the contribution by B is acknowledged by A in third turn position, where she echoes part of B's utterance.

According to Bockgård (2004), slot fillers are the least frequent category, whereas both extensions and completions are more frequent in his data. Contrary to extensions and completions, slot fillers are strongly projected in the interaction and are heard as non-optional in the context. Completions and particularly extensions are less strongly - if at all - projected in the interaction, and B may choose not to participate in the collaborative turn construction, without being held accountable for such a choice. A further difference between the three subtypes concerns the content of the turn. Slot fillers by definition deal with B-events, whereas this is not a requirement for completions and extensions.

\section{$3 \quad$ Method and data}

Our methodological approach is based on conversation analysis (CA), which basically means that we are looking at how the participants in the conversations relate to the interactional challenges of fulfilling a social action by construing a joint meaning, establishing coherence in their talk and sharing the conversational space for this.

For the present study, conversations where one or more of the participants stutter, were recorded on video tape. A broad discourse transcription of the verbal parts of the recordings was produced based on the transcription system developed by Du Bois, Schuetze-Coburn, Cumming and Paolino (1993) (cf. the appendix). The transcriptions and the recordings were used for identification of sequences containing collaboratively constructed turns in the data. This identification procedure was conducted by each of the two authors individually as well as in joint data sessions. The further analysis of the selected sequences was based on repeated viewings of the recordings combined with more detailed transcriptions of the relevant sequences. 
Data for the present study have been selected from a larger data set consisting of approximately 4.5 hours of videotaped conversations. In total, there are fourteen videotaped dyadic conversations, varying in length from ten to twenty-five minutes, involving twelve dyads of speakers. With one exception these dyads consist of one PWS (a teenager or young adult) and one non-stuttering participant (a speech and language therapy student). One of the dyads consists of two male teenagers who stutter. In most of these dyads, the participants are unacquainted. In the majority of the interactions there are very few examples of collaboratively constructed turns. In four of the conversations, however, there is more than the occasional example of the kind of sequential structure that we are interested in. Hence, for the present study, we focus on these four conversations involving two dyads of speakers: Roger and Eric, and John and Helen ${ }^{8}$.

Roger and Eric are two seventeen year old boys who stutter quite severely since childhood. They are both native speakers of Norwegian, and neither of them has any history of dyslexia, specific language impairment or attention deficit disorder. Over several years they have received individual and group therapy related to their fluency disorders. Despite individual variation, both Roger and Eric display severe stuttering with frequent and hard blocks, sound prolongations and repetitions of sounds and syllables in their speech production. Severe stuttering is often accompanied by tension and struggle, as well as escape and avoidance behaviours (Bloodstein and Ratner, 2008; Shapiro, 2011). Secondary symptoms in the form of an inappropriate breathing pattern (heavy inhalations) and the use of facial gestures are easily observable in Roger's speech production. Likewise, Eric displays secondary symptoms of stuttering in the form of inappropriate head and eye movements.

Roger and Eric knew each other from a few previous meetings at a national centre for speech and language therapy in Norway, and they were close in age and social background. In other words, they had a firm common ground basis on which to structure and build their verbal interaction.

For this study, Roger and Eric participated in a total of three joint conversations. Two of these conversations took place during a week in which they were both residents at the national centre for speech and language therapy, while the third conversation took place one month later. For these conversations the participants were presented with ready-made and fairly 'safe' topics for discussion, such as 'What would you have done if you had won a lot of money in the lottery?', 'How do you image your life to be in ten years from now?'.

During the week at the therapy centre, Roger and Eric received individual as well as joint therapy aimed at making their speech more fluent and enhancing their awareness of what it takes to participate in a joint conversation with a particular focus on improvement of listening skills (Sønsterud, Mørk and Lind, 2007). As part of the individual therapy, an integrated intensive approach was used which included both stuttering modification strategies (especially pull-outs) and fluency-shaping techniques. The therapy was individually designed for each of the participants, taking into account their specific type and degree of stuttering and their particular reactions to their stuttering. Some common components of the therapy included confrontation of words starting with different sounds, experimenting with different tension levels, working on lighter articulatory contacts and regulation of speech rate. We also worked on attitude issues, aiming for a more accepting attitude towards their own stuttering. The teenagers worked actively on their stuttering for about six hours each day, with approximately two hours for individual therapy and the rest for general, interactional therapy. During this week, and as part of the transfer work, they were encouraged to try to use the 
fluency skills in both structured and unstructured communicative situations. In addition to this, and as a part of the joint therapy work, they were also encouraged to attempt to explore their stuttering behaviours, cognitions and emotions connected to their speech.

The fourth conversation involves John, a twenty-one year old student who stutters rather severely, and Helen, a twenty-eight year old student of speech and language therapy. They are both native speakers of Norwegian. John has a history of stuttering since childhood, and for much of this period he has received stuttering therapy. He has no history of dyslexia, specific language impairment or attention deficit disorder. His speech production is characterised by sound and syllable repetitions, prolongations and severe blocks. He also displays secondary symptoms, such as muscular tensions and struggle behaviours.

The conversation between John and Helen took place during a week in which John participated in a course for young adult PWSs at the national centre for speech and language therapy. During this week John received individual as well as group therapy aimed at enhanced fluency and a more accepting attitude towards his own stuttering. In particular we worked on prolongation of particular speech segments and a more relaxed breathing pattern in relation to speaking. The therapy focus may have influenced John's verbal interaction and social participation during the course week. It seemed to us that his speech production improved and that his willingness to speak increased during this week (cf. e.g. Spencer, Packman, Onslow and Ferguson (2009) for a discussion of how therapy may influence language use in PWSs).

Together with other speech and language therapy students Helen also participated in the course as part of her practical training. Coincidentally, it turned out that John and Helen were formerly acquainted. They grew up in the same neighbourhood, and thus had prior knowledge of each other and their respective families. As part of a pilot project on verbal interactions between PWSs and speech and language therapy students (Lind, Mørk and Sønsterud, 2007), John and Helen volunteered to participate in a videotaped conversation lasting for about twenty minutes. There was no pre-set topic for this conversation.

\section{$4 \quad$ Analysis}

Below transcribed extracts exemplifying various types of co-constructed turns in our data are presented and described. Further accounts for and implications of the findings are presented and discussed in section 5 .

\subsection{Slot fillers}

Slot fillers are found in the conversations between Roger and Eric as well as in the conversation between John and Helen. The example in (5) is one illustration.

(5) Roger and Eric talking about school

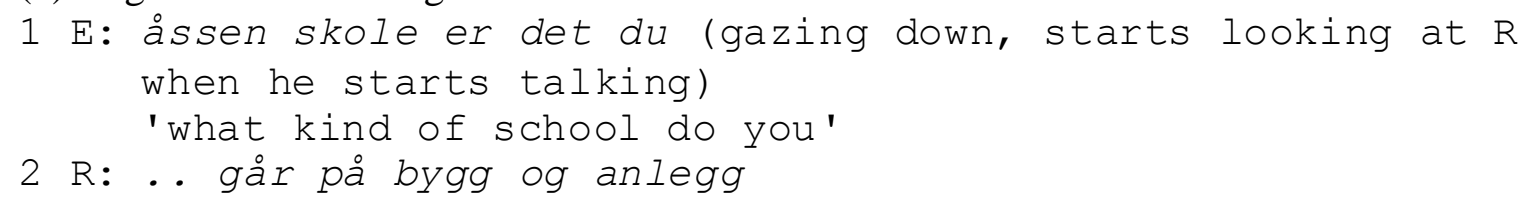




\section{'go to construction and technology' \\ $3 \mathrm{E}:(\mathrm{NODS})$}

In (5) Eric starts producing an utterance in the form of a wh-question, but stops before he has completed it syntactically. The question concerns a B-event, something that the other participant has primary knowledge of. The slot which is left open in Eric's utterance is the main verb slot, and in the next utterance Roger fills in this slot with the expected verb and preposition. A syntactically complete version of the wh-question that Eric starts on, could be: Assen skole er det du går på? 'What kind of school do you go to?' In addition to proving the elements that are required in the wh-question, Roger also - in the same turn - responds to the question by adding a noun phrase referring to the kind of school he goes to. The whole coconstructed turn thus exemplifies an apokoinu or pivot construction, a blend of two clauses (Norén and Linell, 2013).

The sequence in (6) is a further example.

(6) John and Helen talking about their ages

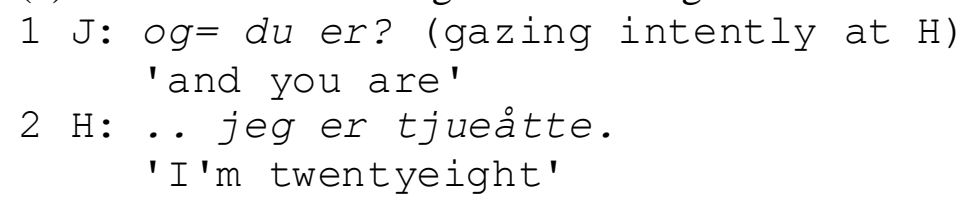

In (6) John produces a question about a B-event (something that Helen has primary knowledge of) in the form of a syntactically incomplete construction with a questioning intonation contour (line 1). A slot is left open for Helen to fill in, as she does in line 2 with an utterance which includes a deictically adjusted repetition of the constituents already provided by John as well as the requested noun phrase. It may be argued that this sequence does not really exemplify a co-constructed turn as Helen's response is not syntactically dependent on the previous turn. We would argue though that the sequence in (6) should be included as an example of co-construction, since the main part of Helen's utterance is the noun phrase filling the open slot in John's utterance, and the rest of her utterance merely repeats - in a deictically adjusted way - the components of his utterance. Repetition of words and phrases within syntactically complete (or incomplete) utterances is not unusual.

Furthermore, in this last example it also seems clear from John's non-verbal behaviour (an intent gaze directed at Helen) that he intends for her to complete the turn. However, looking at the other participant during the first part of a co-constructed turn does not seem to be an obligatory component of co-constructed turns, cf. example (5) where Eric does not look at his co-participant during the utterance of the first part of the turn. He only starts looking at Roger when Roger starts responding.

\subsection{Extensions}

We also find examples of extensions in our data, as in (7) and (8).

(7) John and Helen discussing music and rock bands

$1 \mathrm{H}$ : men de hadde i hvert fall noen hiter,

'but they had at least some hits'

2 ... (2) (Helen turns away to put down her glass)

$3 \mathrm{~J}:$.. <PIANO på nittitallet eller noe sånt. PIANO> 
'in the nineties or so'

In (7), John adds an adverbial phrase (line 3) to a syntactically complete utterance by Helen (line 1). The adverbial phrase is nicely linked to Helen's utterance syntactically, prosodically and semantically. In this example we also see how an extension may be delayed. There is a pause of about 2 seconds (line 2) between Helen's utterance and John's extension. In this pause, Helen turns away to put down her glass of water. Since her utterance is not delivered with a definitely final intonation contour, one interpretation of the pause may be that John is waiting for her to complete the turn. When she does not do so - not even after having put down her glass (cf. the short gap before John starts his utterance in line 3) - he produces an adverbial phrase with a final intonation contour which in effect completes the turn.

(8) Roger and Eric talking about how they imagine their lives in ten years

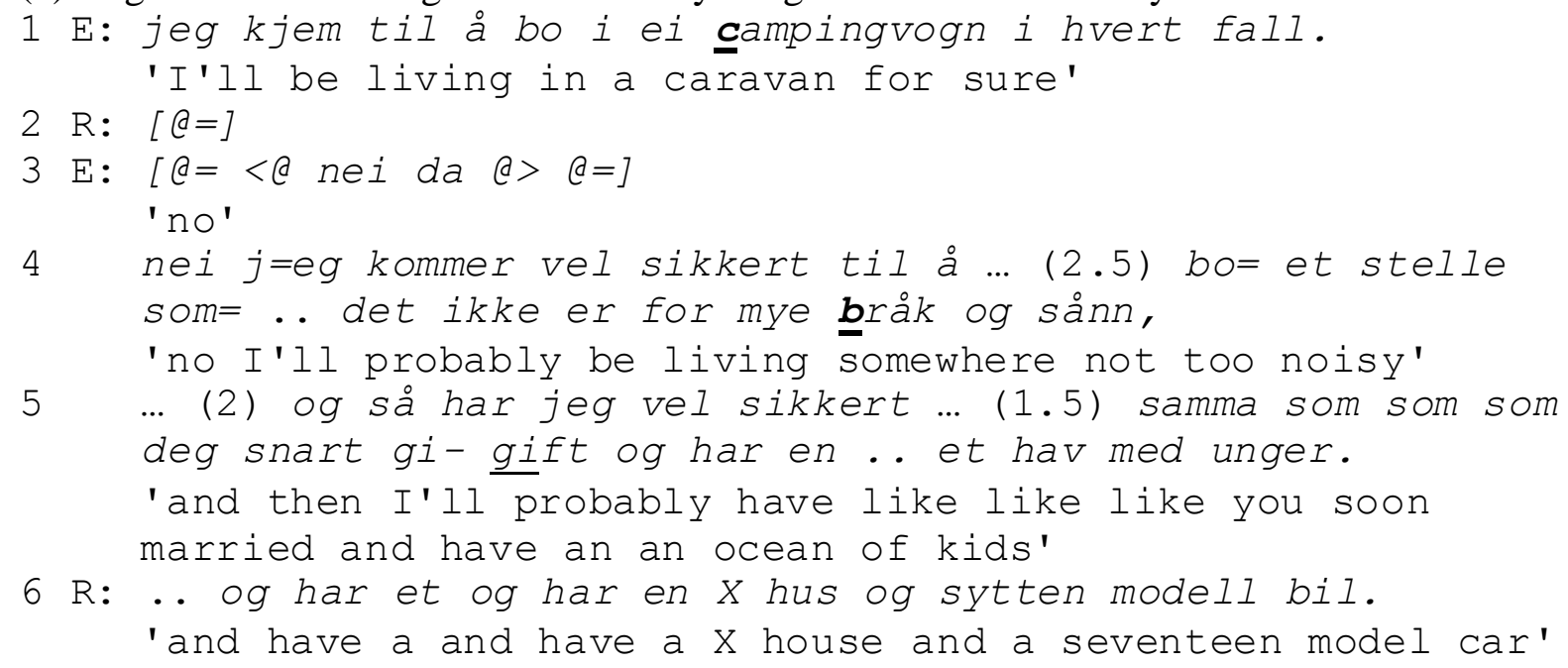

In (8), Roger and Eric are talking about how they imagine their lives to be in ten years' time. Roger extends a turn by Eric by adding a further clause elaborating on the topic that Eric is talking about. Eric's turn is potentially complete in line 5, where the last segment of his contribution is delivered with a final intonation contour. Nevertheless, Roger comes in and extends the turn by a further clause that is linked to Eric's utterance syntactically, semantically and pragmatically (line 6). This example illustrates how a turn may have several possible point of completion. In this case there are two possibilities, following lines 5 and 6 , respectively. Of course, only one possibility is actually realized in the interaction, in this case the turn is completed after Roger's extension in line 6 .

\subsection{Completions}

The third type of co-constructed turn type is the completion, which as mentioned may be preceded by some sign of trouble on the part of the first speaker. In example (9), Roger and Eric are talking about the costs of obtaining a driving licence.

(9) Roger and Eric talking about obtaining a driving licence

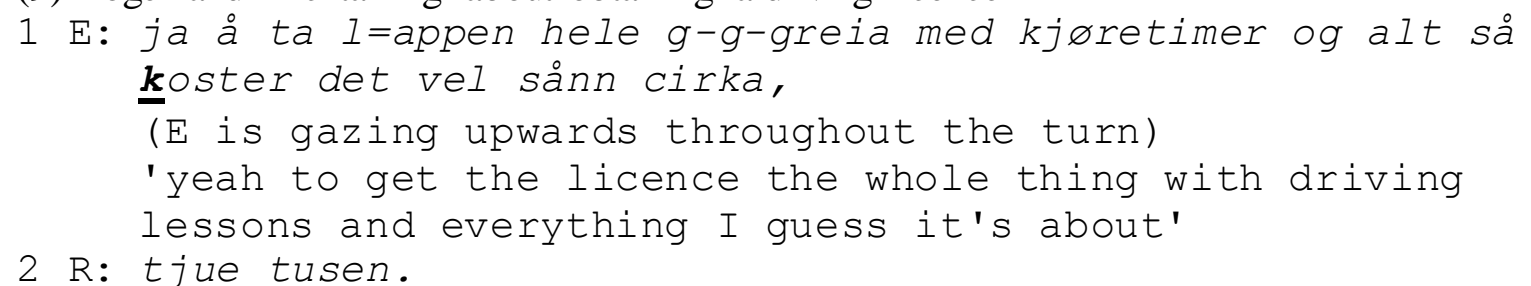


$3 \mathrm{E}: \mathrm{ja}$.

'twenty thousand'

'yes'

There are some signs of uncertainty on Eric's part (line 1) which are reinforced by a lack of eye contact with his interlocutor. Rather than waiting for Eric to finish the utterance, Roger completes the turn by producing a syntactically and semantically appropriate noun phrase (line 2), which is linked to Eric's prior utterance. With a minimal responsive utterance (line 3) Eric acknowledges Roger's contribution, and the preceding turn is in effect unproblematically constructed by the two speakers in collaboration.

A similar example is found in (10), where the boys are talking about dressing up as a ghost and scaring Roger's mother.

(10) Roger and Eric talking about play-acting as a ghost

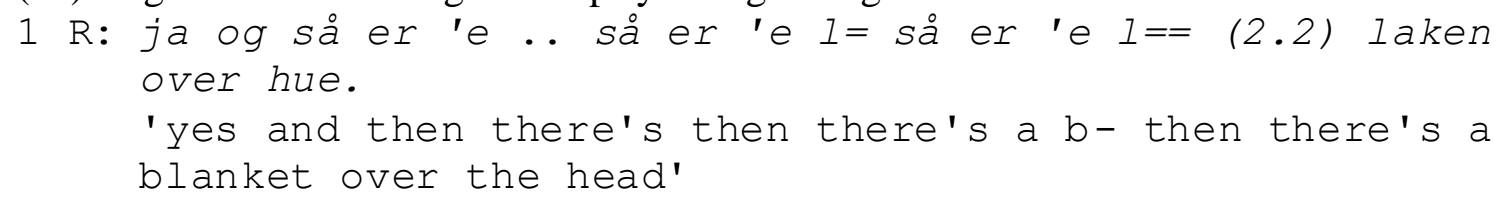

2 E: ja.

'yes'

3 R: .. kommer sånn derre ja (raises his arms slightly)

'comes like yeah'

$4 \mathrm{E}: \ldots b \varnothing$ !

'buh'

$5 \mathrm{R}:[\mathrm{e}=]$

$6 \mathrm{E}:[\mathrm{e}=]$

In this example Eric completes Roger's turn by producing the citation or direct reported speech part (line 4) that is lacking in Roger's utterance (line 3). The collateral laughter which follows this completion (lines 5 and 6) signals a joint acknowledgement of this collaboratively constructed turn regarding form as well as content.

Also in the conversation between John and Helen we find completions, as in example (11).

(11) John and Helen talking about personal interests

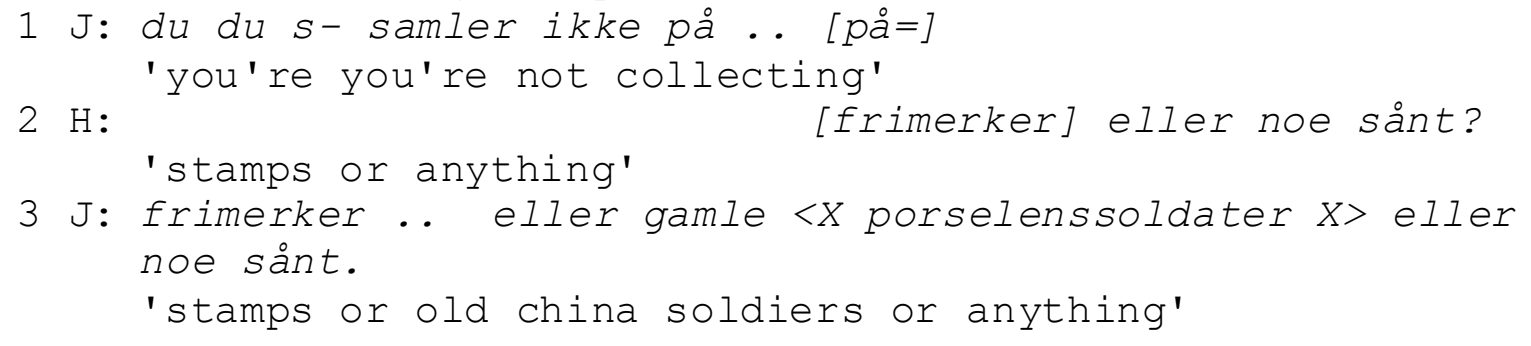

John and Helen are talking about personal interests. There is some indication of trouble towards the end of John's utterance in line 1, where he prolongs the pronunciation of the word $p a ̊$ 'on' as well as repeating it. ${ }^{9}$ Helen comes in and completes the turn with her utterance frimerker eller noe sånt 'stamps or anything' (line 2) which is linked to John's utterance syntactically, semantically and prosodically. John acknowledges the appropriateness of Helen's completion by repeating parts of it and expanding upon it in his next utterance (line $3)$. 
There are also sequences in the data where the completion is produced in overlap by the two participants, as in examples (12) and (13).

(12) John and Helen talking about music

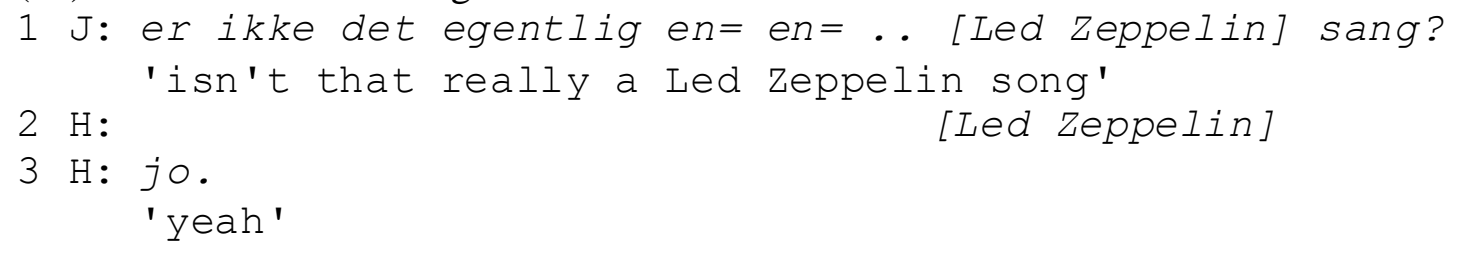

(13) John and Helen talking about music

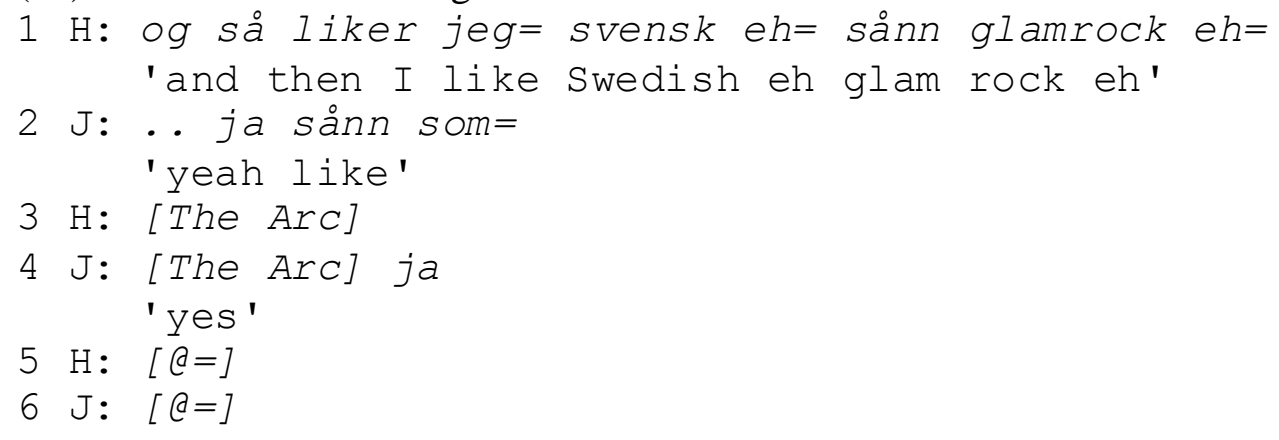

In each of these examples there are signs of trouble, in the form of repetitions and prolongations, indicating a search for the appropriate word or phrase. And in both of the examples both of the participants evidently feel responsible for finding the right expression. The noun phrases they search for end up being produced simultaneously by the two of them in both examples.

Furthermore, in these two examples the incomplete utterances which make up the first part of the co-constructed turn (the first part of line 1 in (12) and line 2 in (13)) are produced in a format which projects the co-participant as a knowing recipient. In (12) the construction er ikke det egentlig 'isn't that really' carries with it the implication that the recipient knows whatever it is the utterance is referring to. Likewise, in (13) the construction sånn som 'like/such as' implies a knowing recipient.

\subsection{An odd example?}

As the excerpts in (5)-(13) illustrate, we have found examples of all the types of collaborative turn constructions that Bockgård (2004) describes in dyadic conversations where at least one of the participants is a PWS. When examining the videotaped conversation between John and Helen, there was one sequence in which the turn taking pattern struck us as somewhat peculiar, though. In this sequence the format of one of the verbal utterances by John seems to lay the floor for the use of a slot filler. However, Helen does not produce any slot filler. Hence, we were curious about why a collaborative construction was not realised in this particular sequence. The sequence is presented in (14).

(14) John and Helen talking about Helens education and future career plans

1 J: og $d u=e r . . d u=$ er altså .. forskolelærer, 'and you are you are a pre-school teacher' 


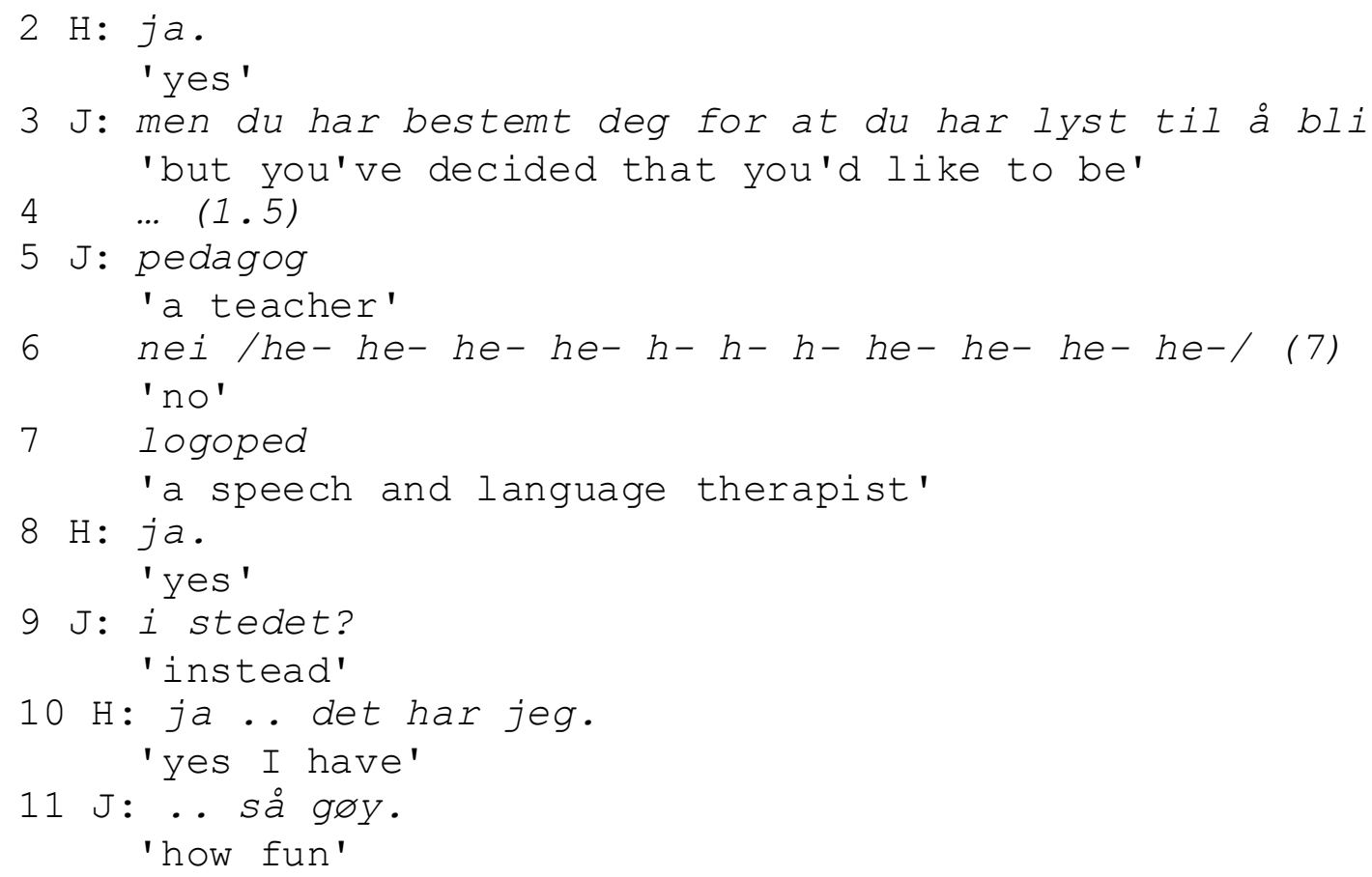

In this sequence, John and Helen are talking about her education and future career plans. In line 3 John produces a syntactically incomplete declarative utterance concerning a B-event (something that primarily concerns Helen). John seems to have problems finding and/or producing the correct noun phrase referring to Helen's future profession, namely 'speech and language therapist'. The syntactically incomplete utterance in line 3 is thus followed by a pause of about 1.5 seconds (line 4). In verbal interaction this is a fairly long pause (Jefferson 1989), and given the format and content of John's incomplete turn in line 3, Helen could very well have produced a turn completing contribution (a slot filler) at this point, that is, starting during the break in line 4. However, she does not produce any utterance at this point, and instead in line 5, John produces the noun phrase pedagog 'teacher'. This is not the appropriate noun phrase though for referring to Helen's future occupation. Hence, at this point (following line 5), there is an opportunity for Helen to initiate a repair in next turn position. However, she does not initiate repair on John's utterance, and examining the sequence closely on video tape, we find evidence of an internal, non-verbal factor which contextualizes the rest of John's turn as a self-initiated self-repair. Throughout this sequence, the participants are looking at each other, except for the part of John's turn in line 6 where he utters the word nei 'no' while shaking his head, and then he closes his eyes for about 7 seconds while repeating the syllable /he/. His subsequent production of the word he was aiming for (logoped 'speech and language therapist') (line 7) is finely coordinated with the resumption of eye contact with Helen. In other words, in this sequence John uses a quite strong signal, viz. deliberate avoidance of eye contact, to signal that he will carry out the whole repair sequence himself. This use of gaze behaviour in relation to problematic sequences has also been described by for instance Tetnowski and Damico (2001) and Rhys (2005).

\section{$5 \quad$ Discussion and conclusion}

In the data that we have focussed on in this study, we have found collaboratively constructed turns of various types - slot fillers, extensions and completions - in dyadic conversations where at least one of the participants is a PWS. As mentioned the data for the present study is a subset of a larger set of conversations involving at least one PWS. In the majority of these conversations, there are hardly any examples of collaboratively constructed turns. In other 
words, for the present study we have deliberately selected a small portion of the empirical data which could highlight the phenomenon we wanted to focus on.

Furthermore, even though a selective case study as the present cannot contribute directly to general conclusions in the 'traditional "distributional" understanding of generalizability' Peräkylä (1997: 215), it can contribute to an exploration and understanding of the 'possibilities of language use [which are] the central objects of all conversation analytic case studies on interaction in particular institutional settings' (Peräkylä 1997: 215, italicised in the original). Such possibilities of language use are potentially general across different settings, even though they are not necessarily realised - or realised in the same manner - in all settings. Finally, since scientific progress is cumulative in nature, the results of a single case study can contribute to strengthening or weakening results of earlier studies.

There may be several different reasons for the unequal distribution of collaboratively constructed turns in the total data set (fourteen conversations). Differences in individual speech style (Johnstone, 1996), is one possible factor contributing to the distributive variation. Another factor is gender differences among the participants in the various dyads (Eckert and McConnell-Ginet, 2013). Unfortunately, our data set gives us little opportunity to investigate this factor, as there is relatively little variety in the gender constellations in the various dyads. For instance, we have no male speech and language therapy students in our data; there are generally very few male students of speech and language therapy in Norway. Hence, the only male-male conversations we have in the data set, are the ones between the two teenagers who stutter (Roger and Eric). Furthermore, there was only one female PWS in our data. Most of the dyads then consist of a female speech and language therapy student and a male PWS. In all likelihood this is a fairly common constellation in speech and language therapy contexts, and it is one which clearly warrants consideration in clinical practice as well as in research.

A further factor contributing to the unequal distribution of collaboratively constructed turns in our data, is the variation in the degree of common ground between the participants in the different dyads (Clark, 1996). In the four conversations where we have found most examples of collaboratively constructed turns (i.e. the conversations that we have focussed on in this study), the participants are previously acquainted to a certain extent. They have met and talked to each other on previous occasions and thus presumably have a larger pool of shared knowledge to build on in their conversation than what is the case in the rest of the dyads.

With the exception of the conversations between the two teenagers who both stutter (Roger and Eric), there is an a priori asymmetry between the speakers on several levels in most of the conversations in our data set. Firstly, there is an asymmetry regarding speech fluency; one of the participants is a PWS, and one is not in these dyads. Secondly, there is an asymmetry regarding the interactional roles in this particular communicative setting. All of the conversations took place at a national centre for speech and language therapy in Norway, where PWSs can come for weekly courses in which speech and language therapy students also participate as part of their practical training. In other words, the context is one in which the PWS is a client, and the interlocutor is a professional (to be). In this type of institutional context, the expectations of a particular communicative genre or activity type (Levinson, 1979; Linell, 1998) are often salient. Some of these expectations may concern the distribution of speaker roles and the types of contributions that each of the participants is obliged, expected or allowed to make. The manifestation of an activity type is the result of an interplay between overarching contextual (including cultural) expectations and the actual contributions 
that are made in the particular context of communication. Hence, there is an interdependent relation between act and activity (Linell, 1998).

In the conversations that we have not focussed on in this study, the expectations related to the activity type are evident in the division of communicative labour between the participants. In most of these conversations, the speech and language therapy students clearly adopt the role as 'interviewer', and the PWSs mostly seem content with responding without taking responsibility for topical progression in the interaction. Given this particular division of communicative labour, it would not have been unreasonable to expect more examples of the slot filler construction in more of the conversations. Bockgård (2004) for instance finds that such constructions are overrepresented in the doctor-patient interactions in his data, and he accounts for this by referring to fact that such conversations in general contain many questions about B-events.

Another way of looking at this, however, is to evoke the concept of ideology in interaction (van Dijk, 1997). van Dijk characterises ideologies as 'shared self-definitions of groups that allow group members to coordinate their social practices in relation to other groups' (van Dijk, 1997: 26). In this sense, ideologies contain criteria of 'typical actions and aims (What do we do, and why?) [and] norms and values (What is good and bad for us?)' (van Dijk, 1997: 26). The types of advice that are regularly passed on to parents, teachers and others interacting with PWSs, exemplified in (1) above, can be seen as resulting from a particular interactional ideology that is found in relation to communication and stuttering. We also assume that this ideology is part of the (implicit) background knowledge of speech and language therapy students. In other words, the fact that we do not see more examples of co-constructed turns particularly slot fillers - in more of the conversations in our data set, may be accounted for with reference to an assumedly very strong interactional ideology overriding the expectations related to the particular activity type at hand. The relative strength of this interactional ideology related to conversations with PWSs may also explain the seemingly peculiar lack of a slot filler in example (14) above.

So far we have pointed out some external factors that may account for the unequal distribution of collaboratively constructed turns in the total data set: individual speech styles, a lack of common ground, expectations related to a particular activity type and expectations related to an overarching ideology of interaction. It is important to remember that there may be more than one valid account for the lack or presence of collaboratively constructed turns in these conversations. Furthermore, in addition to external factors, we have seen (example 14), that an internal factor - a contextualisation cue (Gumperz, 1982) such as gaze behaviour - may also influence the use (or non-use) of collaboratively constructed turns in the data. As mentioned, based on our data we cannot conclude though that a particular type of gaze behaviour (either gazing at the co-participant or withdrawing one's gaze) is unequivocally linked to a particular type of turn-taking behaviour (cf. e.g. examples (5) and (9) above where turns are collaboratively constructed in the absence of gaze contact). ${ }^{10}$ Further empirical studies based on data from more speakers in more diverse contexts are needed to explore how and to what extent co-construction of turns may be interactionally invited.

Another empirical question concerns the relationship between word searching and coconstruction. In some of the examples we have looked at (e.g. 9, 11, 12 and 13), there are signs that speaker A is searching for a word, and that this may be a reason for the resulting coconstructed turns in each of the examples. However, far from all of the examples in our data 
contain signs of word finding difficulties. In other words it is as yet hard and perhaps not very useful to attempt to draw a very firm line between these two categories.

As mentioned in the introduction, co-construction of turns may initially remind us of the concept of interruption. However, although seemingly quite similar, co-constructed turns and interruptions are fundamentally different types of behaviour, with regard to form, but perhaps most importantly, with regard to function. Whereas interruptions usually imply a negative interference with a contribution by another participant, co-constructions generally have a positive social effect on the interaction (Bockgård, 2004). Co-construction can be a supportive way of displaying interest, involvement and engagement in the interaction.

Furthermore, it seems possible to differentiate between interruptions and co-constructions with reference to Goffman's seminal work on production and reception roles in interaction (Goffman, 1979; cf. also Levinson, 1988). Rather than assuming two single, and internally coherent, participant roles - speaker and hearer - Goffman demonstrates how both the production roles and the reception roles must be dissected into different roles. On the production side, which is most relevant in the present context, Goffman distinguishes between three roles: animator, author and principal. The animator is the 'individual active in the role of utterance production', the author is the one 'who has selected the sentiments that are being expressed and the words in which they are encoded', and the principal is the one 'whose position is established by the words that are spoken, someone whose beliefs have been told, someone who is committed to what the words say' (Goffman 1981 [1979]: 144). These three roles may be united in one and the same individual, or they may be embodied by two or more individuals. Clark (1996: 10) claims that '[i]n face-to-face conversation, the participants are in full control. They speak for themselves, jointly determine who says what when, and formulate their utterances as they go'. In other words, face-to-face informal conversation is claimed to be characterised by a unity of all three production roles within one speaker at a time. There are, however, important exceptions to this, for instance the use of reported speech where the role of animator is separated from and independent of the roles of author and/or principal (Couper-Kuhlen, 1999). We would claim that the same is prototypically the case with collaboratively constructed turns. In such turns participant B takes on a role as animator in Goffman's sense, but the contribution is essentially oriented towards participant A as author and/or principal of the turn. This feature distinguishes collaboratively constructed turns from interruptions, where participant $\mathrm{B}$ (who interrupts participant $\mathrm{A}$ ) does not give voice to someone else's words and/or opinions, but in fact expresses his/her own position on a topic.

The fact that collaboratively constructed turns are common in verbal interaction, and that such sequences differ from interruptions in form as well as in function, are important insights for clinical practice as well as for everyday communication involving persons with some form of speech or language impairment. Rather than offering the kind of context-free advice cited in (1) above, a potentially more fruitful strategy could be to discuss the individual experience (the pros and cons) of collaboratively constructed turns with the PWS as well as with his/her interlocutors (family, friends, teachers, colleagues etc.). The types of questions to ask could be: In what contexts do you experience problems or feel uncomfortable with other participants' 'interfering' with your turn, and in what contexts is it unproblematic or even desirable? Raising the individual's awareness of what is going on in various interactional contexts, could potentially empower the person to deal with interactional challenges in a more pro-active and constructive manner. This is in all likelihood not an easy endeavour though, as the notion of an individualistic speakership seems to be enmeshed in our everyday practices (Auer, 2014). 
As our empirical study has shown, the use and functions of collaboratively constructed turns are context sensitive, which highlights the need for qualitative and context sensitive approaches to research as well as therapy within the field of fluency disorders. Language use takes place in interactional contexts and involves individuals in dialogical meetings (Linell, 2009). Hence, when working with language and language use we need to take into account the roles and behaviours of all the participants as well as the role of the wider context in which language and interaction are embedded. In research, qualitative and context sensitive approaches may lead to a disclosure of aspects of a speech and language disorder that are hard or even impossible to detect using experimental and/or quantitative approaches. Examining language in an interactional context also more easily allows us to look for potentials, skills and positive aspects of communication in individuals with speech and language disorders, as has been demonstrated in relation to aphasia in various cultural and linguistic contexts (cf. e.g. Beeke, Wilkinson and Maxim, 2007; Goodwin, 1995; Klippi, 1996; Lind, 2005).

Findings from qualitative research may be used to improve therapy for instance by raising the awareness of the speech and language therapist as well as the client with regard to language, communication and the particular type of disorder in question. A qualitative research methodology such as conversation analysis may thus be adapted into a direct and practical tool in therapy, as has been done in relation to aphasia (e.g. Lock, Wilkinson and Bryan, 2001). For clinical decision making as well as individually targeted therapy, advice and tasks must be individually - and contextually - adapted, as pointed out by e.g. Huber, Packman, Quine, Onslow and Simpson (2004) and Manning (2007). In essence, this amounts to a requirement to pay respect to the extensive individual variation in the field of fluency disorders and speech and language disorders in general. This variation concerns not only symptoms, adaptations and coping, but also the needs and benefits of the individual in therapy. 


\section{References}

Acton, C. (2004) A conversation analytic perspective on stammering: Some reflections and observations. Stammering Research 1: 249--270.

(http://www.stamres.psychol.ucl.ac.uk/stammering. issue3.pubd.htm)

Auer, P. (2014) The limits of collaboration - Speakership in conversation with persons with aphasia. In M.J. Ball, N. Müller and R.L. Nelson (eds.) Handbook of Qualitative Research in Communication Disorders 187--206 New York: Psychology Press.

Beeke, S., Wilkinson, R. and Maxim, J. (2007) Individual variation in agrammatism: a single case study of the influence of interaction. International Journal of Language \& Communication Disorders 42: 629--647.

Bloodstein, O. and Ratner, N.B. (2008) A Handbook of Stuttering (6th ed.). Clifton Park, NY: Delmar.

Bockgård, G. (2004) Syntax som Social Resurs. En Studie av Samkonstruktionssekvensers Form och Funktion i Svenska Samtal. Uppsala universitet: Institutionen för nordiska språk.

Bothe, A.K. and Andreatta, R.D. (2004) Quantitative and qualitative research paradigms: Thoughts on the quantity and creativity of stuttering research. Advances in SpeechLanguage Pathology 6: 167--173.

Cheek, J., Onslow, M. and Cream, A. (2004) Beyond the divide: Comparing and contrasting aspects of qualitative and quantitative research approaches. Advances in SpeechLanguage Pathology 6: 147--152.

Clark, H.H. (1996) Using Language. Cambridge: Cambridge University Press.

Couper-Kuhlen, E. (1999) Coherent voicing: On prosody in conversational reported speech. In W. Bublitz, U. Lenk and E. Ventola (eds.) Coherence in Spoken and Written Discourse 11--33. Amsterdam: John Benjamins.

van Dijk, T.A. (1997) Discourse as interaction in society. In T.A. van Dijk (ed.) Discourse as Social Interaction. Discourse Studies: A Multidisciplinary Introduction. Volume 2 1-37. London: SAGE Publications Ltd.

Du Bois, J.W., Schuetze-Coburn, S., Cumming, S. and Paolino, D. (1993) Outline of discourse transcription. In J.A. Edwards and M.D. Lampert (eds.) Talking Data. Transcription and Coding in Discourse Research 45--87. Hillsdale, New Jersey: Lawrence Erlbaum.

Eckert, P. and McConnell-Ginet, S. (2013) Language and Gender. Cambridge: Cambridge University Press.

Ford, C.E., Fox, B. and Thompson, S.A. (2002) Introduction. In C.E. Ford, B. Fox and S.A. Thompson (eds.) The Language of Turn and Sequence 3--13. Oxford: Oxford University Press.

Goffman, E. (1979) Footing. In E. Goffman (1981) Forms of Talk 124--159. Oxford: Blackwell.

Goodwin, C. (1995) Co-constructing meaning in conversations with an aphasic man. Research on Language and Social Interaction 28: 233--60.

Gumperz, J.J. (1982) Discourse Strategies. Cambridge: Cambridge University Press.

Hayhow, R. and Stewart, T. (2006) Introduction to qualitative research and its application to stuttering. International Journal of Communication Disorders 41: 475--493.

Huber, A., Packman, A., Quine, S., Onslow, M. and Simpson, J. (2004) Improving our clinical interventions for stuttering: Can evidence from qualitative research contribute? Advances in Speech-Language Pathology 6: 174--181. 
Jefferson, G. (1989) Preliminary notes on a possible metric which provides for a 'standard maximum' silence of approximately one second in conversation. In D. Roger and P. Bull (eds.) Conversation. An Interdisciplinary Perspective 166--196. Clevedon: Multilingual Matters.

Johnstone, B. (1996) The Linguistic Individual. Self-Expression in Language and Linguistics. Oxford: Oxford University Press.

Kelly, E.M. (1994) Speech rates and turn-taking behaviours of children who stutter and their fathers. Journal of Speech and Hearing Research 37: 1284--1294.

Kelly, E.M. and Conture, E.G. (1992) Speaking rates, response time latencies, and interrupting behaviors of young stutterers, nonstutterers, and their mothers. Journal of Speech and Hearing Research 35: 1256--1267.

Klippi, A. (1996) Conversation as an Achievement in Aphasics. Helsinki: Suomalaisen Kirjallisuuden Seura.

Labov, W. and Fanshel, D. (1977) Therapeutic Discourse: Psychotherapy as Conversation. Orlando, Florida: Academic Press.

Lerner, G.H. (1996) On the "semi-permeable" character of grammatical units in conversation: conditional entry into the turn space of another speaker. In E. Ochs, E.A. Schegloff and S.A. Thompson (eds.) Interaction and Grammar 238--276. Cambridge: Cambridge University Press.

Lerner, G.H. (2002) Turn-sharing. The choral co-production of talk-in-interaction. In C.E. Ford, B. Fox and S.A. Thompson (eds.) The Language of Turn and Sequence 225-256. Oxford: Oxford University Press.

Levinson, S.C. (1979) Activity types and language. Linguistics 17: 365--399.

Levinson, S.C. (1988) Putting linguistics on a proper footing. In P. Drew and A. Wootton (eds.) Erving Goffman. Exploring the Interaction Order 161--227. Cambridge: Polity Press.

Lind, M. (2005) Conversation - more than words. A Norwegian case study of the establishment of a contribution in aphasic interaction. International journal of applied linguistics 15: 213--239.

Lind, M., Mørk, M. \& Sønsterud, H. (2007) Blikk og samhandling i kommunikasjon med personer som stammer. Norsk tidsskrift for logopedi 53(4): 12--17.

Linell, P. (1998) Approaching Dialogue. Talk, Interaction and Contexts in Dialogical Perspectives. Amsterdam/Philadelphia: John Benjamins Publishing Company.

Linell, P. (2009) Rethinking Language, Mind, and World Dialogically. Interactional and Contextual Theories of Human Sense-Making. Charlotte, NC: Information Age Publishing.

Livingston, L.A., Flowers, Y.E., Hodor, B.A. and Ryan, B.P. (2000) The experimental analysis of interruption during conversation for three children who stutter. Journal of Development and Physical Disabilities 12: 235--266.

Lock, S., Wilkinson, R. and Bryan, K. (2001) SPPARC (Supporting Partners of People with Aphasia in Relationships and Conversation): A Resource Pack. Bicester: Speechmark Press.

Manning, W.H. (2007) Clinical Decision Making in Fluency Disorders. (2 ${ }^{\text {nd }}$ ed.). Vancouver: Singular Thomson Learning.

Meyers, S.C. and Freeman, F.J. (1985) Interruptions as a variable in stuttering and disfluency. Journal of Speech and Hearing Research 28: 428--435.

Norén, N. and Linell, P. (2013) Pivot constructions as everyday conversational phenomena within a cross-linguistic perspective: An introduction. Journal of Pragmatics 54: 1--15.

Peräkylä, A. (1997) Reliability and validity in research based on tapes and transcripts. In D. 
Silverman, D. (ed.) Qualitative Research. Theory, Method and Practice 201--220. London: SAGE Publications Ltd.

Rhys, C.S. (2005) Gaze and the turn: A nonverbal solution to an interactive problem. Clinical Linguistics \& Phonetics 19: 419--431.

Ryan, B.P. (2000) Speaking rate, conversational speech acts, interruption, and linguistic complexity of 20 pre-school stuttering and non-stuttering children and their mothers. Clinical linguistics \& phonetics 14: 25--51.

Sacks, H., Schegloff, E.A. and Jefferson G. (1974) A simplest systematics for the organization of turn-taking for conversation. Language 50: 696--753.

Schegloff, E.A. (2007) Sequence Organization in Interaction. A Primer in Conversation Analysis. Volume 1. Cambridge: Cambridge University Press.

Shapiro D.A. (2011) Stuttering Intervention. A Collaborative Journey to Fluency Freedom. (2nd ed.) Austin, Texas: Pro-ed.

Spencer, E., Packman, A., Onslow, M. and Ferguson, A. (2009) The effect of stuttering on communication: A preliminary investigation. Clinical linguistics \& phonetics 23: 473-488.

Sønsterud, H., Mørk, M. \& Lind, M. (2007) Improvement of fluency and listening skills in teenagers with advanced stuttering. Proceedings of the 2007 IALP Congress. (http://proceedings.ialp.info/contents.htm)

Tetnowski, J.A. and Damico, J.S. (2001) A demonstration of the advantages of qualitative methodologies in stuttering research. Journal of Fluency Disorders 26: 17--42.

Tetnowski, J.A. and Damico, J.S. (2004) Getting out of Procrustes' bed: The needs and benefits of qualitative research in stuttering. Advances in Speech-Language Pathology 6: 153--158. 


\section{Appendix}

Transcription symbols (based on Du Bois et al 1993)

Truncated word

Speech overlap

Transitional continuity

$[\ldots]$

[...] (vertical alignment of the left hand brackets)

Final

Continuing

Appeal

?

Emphasis and lengthening

Booster

Lengthening

Extra lengthening

Blocks

Extra lengthening $=$

Pauses

Long (more than $1 \mathrm{sec}$.)

Short (0.2-0.9 sec.)

Latching

(0)

Vocal and non-verbal signals

Vocal noises

(THROAT CLEARING)

Laughter

$@=$ (extended laughter)

Voice quality

Slow

$<$ SLOW ... SLOW $>$

Soft (piano)

$<$ PIANO ... PIANO $>$

Laugh quality

$<@$...@ $>$

Transcriber's/researcher's perspective

Comment

(comment)

Uncertain hearing

$<\mathrm{X} \ldots \mathrm{X}>$

Indecipherable word

$\mathrm{X}$ 
$\overline{1 \text { www.stammeringcentre.org/ }}$

${ }^{2}$ www.stutteringhelp.org/

${ }^{3}$ Similar types of advice are indeed currently (2013) also found on our own webpage (www.statped.no).

${ }^{4}$ Bockgård (2004) analyses a data corpus of approximately 32.5 hours of audio- and videotaped Swedish conversations in various contexts, including everyday conversation as well as different types of institutional conversations.

${ }^{5}$ Slot fillers, extensions and completions are our translations of the Swedish terms 'luckifyllande svar', 'tillägg' and 'ifyllnader', respectively (Bockgård, 2004).

${ }^{6}$ As Bockgård (2004: 93) points out, the slot filler construction can also be used in instances where speaker A supposedly is the one with greater knowledge of the topic, as in classroom examinations. No such examples are found in our data.

${ }^{7}$ Since we use a slightly different transcription system from Bockgård (2004), we have adapted the examples we present from his study to fit with our notation system. The examples in (2)-(4) are presented in the original Swedish form with an English translation provided by us for the present article. The translations are meant to capture the content of the original, without necessarily aiming for idiomatic English. A key to the transcription symbols is found in the appendix.

${ }^{8}$ All names have been replaced by pseudonyms.

${ }^{9}$ In Norwegian, the phrase 'to collect something' is literally translated as 'to collect on something'.

${ }^{10}$ We may note that Bockgård (2004: 278) also concludes that there is no clear pattern of gaze behaviour in relation to the co-constructed turns in his data. 